\title{
Analysis of Spatial-Temporal Characteristics and Pattern Evolution of Fishery Geographic Agglomeration in China
}

\author{
Rui Yang \\ College of Urban and Environmental Sciences \\ Northwest University \\ Xi'an710127, China \\ Liu Xiaoqiong \\ College of Urban and Environmental Sciences \\ Northwest University \\ Xi'an710127, China
}

\author{
Li Julin \\ College of Urban and Environmental Sciences \\ Northwest University \\ Xi'an 710127, China \\ Zhang Jian ${ }^{1,2}$ \\ ${ }^{1}$ College of Urban and Environmental Sciences \\ Northwest University \\ Xi'an710127, China \\ ${ }^{2}$ College of Silk Road Studies \\ Northwest University \\ Xi'an710069, China
}

\author{
Zhao Xinzheng* \\ College of Urban and Environmental Sciences \\ Northwest University \\ Xi'an710127, China
}

\begin{abstract}
To explore the spatial-temporal characteristics and pattern evolution of geographic agglomeration of Chinese fishery for the period from 1988 to 2013 , a set of indexes which can directly report the spatial-temporal characteristics and pattern evolution of that are used, including the Gini coefficient, gravity model and exploratory spatial data analysis. Results indicate that fishery production shows a heavily uneven distribution and tends to cluster at the province level. Additionally, the barycenter of fishery is always located in southeastern China during the study periods and tends to follow the flow of the Yangtze River over time. Simultaneously, spatial patterns of fishery geographic agglomeration substantially present hot spots in coastal regions and cold spots in inland regions. But the total amount of both hot and sub hot spots has decreased by nearly half while that of both cold and sub cold spots, on the contrary, has increased relatively in the time periods. More importantly, the majority of type areas, including hot spots, sub hot spots, sub cold spots and cold spots haven't yet changed, and the changed ones also mainly showed the gradually weakened evolution characteristics. Moreover, we further found that both distribution trends of contiguity and change rules of gradient for various type areas were not obvious gradually for the period from 1988 to 2013 . We attempt to take a fresh look at the fishery geographic agglomeration by the combination of multi methods and angles, and our empirical evidence has important implications for both theories and policy making. Certainly, this also is innovative points of this paper.
\end{abstract}

Keywords-fishery; geographic agglomeration; spatial-temporal characteristics; pattern evolution; China

\section{INTRODUCTION}

The industrial spatial agglomeration is the most prominent geographical features of economic activities ${ }^{[1]}$ and also is a global economic geography phenomenon, which plays an important role to promote industrial development and regional and national economic growth. Thus, it has also been an important research topic that economic geography and other subjects are interesting ${ }^{[2]}$. But early studies overwhelmingly focused on manufacturing industries ${ }^{[3]}$ and producer services ${ }^{[4]}$ rather than agriculture which also are to need to be further studied. Additionally, features of geographic agglomeration vary with the type and characteristics of industries. Due to the strong dependence on natural conditions, the outstanding regional characteristics and the internal significant differences of agricultural production, detailed studies of agricultural sector therefore should be performed.

Faced with the realistic trends, including theory demands of finer studies, world agricultural agglomeration quickly since $1980 \mathrm{~s}^{[5]}$ and dramatic changes of distribution of Chinese agricultural production, academic researches about agriculture geographic agglomeration are constantly increasing. And a lot

\footnotetext{
* Sponsor: National Natural Science Foundation of China(No.41401184, 41601174),Social Science Foundation of Shaanxi Province, China (No.2015D055), The Science Foundation of Northwest University(No.14NW03)

*Corresponding author: E-mail: xzzhao@nwu.edu.cn
} 
of research of foreign scholars is interesting in empirical studies associating with industrial agglomeration area of special agriculture from industrial cluster perspective ${ }^{[6]}$. Nevertheless, Chinese scholars pay more attention to the pattern evolution of agriculture geographic agglomeration at a large-scale level in recent years, and they have mainly discussed the nationwide agricultural distribution which includes the layout of nationwide farming ${ }^{[7]}$ and animal husbandry ${ }^{[8]}$ and the spatial-temporal characteristics and change trend of geographic agglomeration about all sorts of crops which includes grain ${ }^{[9]}$, cotton ${ }^{[10]}$, vegetable ${ }^{[11]}$, fruit ${ }^{[12]}$ and so on. In general, no matter research methods, objects or scales, domestic academia has a gradual in-depth research for agriculture geographic agglomeration. For example, the Gini coefficient, the specialization index, gravity model and other models have been employed widely in academic study, and the new studies also begin to emerge by using the platform of GIS and the analysis tool of ESDA ${ }^{[13-15]}$. But it's remarkable that, comparing with farming, animal husbandry and forestry, the research about the processes and patterns of Chinese fishery geographic agglomeration is rarely seen ${ }^{[16]}$ in four major sectors of agriculture.

As the world's first production and trading country of fishery, Chinese fishery has developed into an important industry for agriculture and the rural economy, and it has greatly contributed to the national food security, marine power construction and fishermen's income. However, we are still facing many serious challenges, such as the extensive mode of development and the depletion of fishery resources, thereby; the transformation and upgrading of fishery should be duly advocated. Under this background, exploring the spatial-temporal characteristics and pattern evolution of Chinese fishery geographic agglomeration has the practical significance for adjusting the layout of the fishery and optimizing that of catching and breeding space. So, using the Gini coefficient, gravity model and exploratory spatial data analysis, we deliberately investigate the time-series changes of geographic agglomeration degree, the variation range of barycenter distribution and the pattern evolution of geographic agglomeration about Chinese fishery for the period from 1988 to 2013 and expect to provide scientific evidence for relevant policy making.

\section{DAtA AND Methodology}

\section{A. Data}

The data are obtained from the China Statistical Yearbook 1989-2014 (NBSC, 1989-2014), China Fisheries Yearbook 2000-2014 (NBSC, 2000-2014), China Population and Employment Statistics Yearbook 2000; 2014 (NBSC, 2000; 2014), China Regional Economic Statistics Yearbook 2000; 2014 (NBSC, 2000; 2014). And the spatial data are drawn upon the Fundamental Geographic Information Database at a scale of 1:250000. Moreover, we do not include Hong Kong, Macao and Taiwan due to insufficient statistical information, and Chongqing will be incorporated into Sichuan province to guarantee the integrity and continuity of the data.

\section{B. Methodology}

(1) Gini coefficient. The Gini coefficient was employed to proxy the uneven degree of industries distribution ${ }^{[17]}$, such as the case of fishery production. It is defined as follows:

$$
G_{j}=1-\frac{1}{n}\left(2 \sum_{i=1}^{n=1} W_{i j}+1\right)
$$

Where $j$ could represent fishery or its products $(j=0,1,2$, $3,4) ; G_{j}$ is the Gini coefficient whose value is between $0-1$, and the higher the value of $G_{j}$ is the more the distribution of fishery production is considered to be uneven; $\mathrm{n}$ is equal to 6 , which is the number of groups divided by the rank-based yields of fishery products in the sample; $W_{i j}$ is ratio of fishery product yields between group $\mathrm{i}$ of $\mathrm{j}$ and all groups.

(2) Gravity model. To examine the distribution of Chinese fishery, we apply gravity model, originating from Li E L as follows ${ }^{[17]}$ :

$$
\begin{aligned}
& \bar{X}=\sum_{i=1}^{n} G_{i} X_{i} / \sum_{i=1}^{n} G_{i} \\
& \bar{Y}=\sum_{i=1}^{n} G_{i} Y_{i} / \sum_{i=1}^{n} G_{i}
\end{aligned}
$$

Where $n$ is the total number of region, and $i$ is the fraction of the whole region; $G_{i}$ is the fishery product yields of region $\mathrm{i}$ in some sense; then $\left(\mathrm{X}_{\mathrm{i}}, \mathrm{Y}_{\mathrm{i}}\right)$ is the barycentric coordinate for region i. Correspondingly, $(\bar{X}, \bar{Y})$ also is the barycentric coordinate for the whole study area.

(3) Exploratory spatial data analysis (ESDA). ESDA is a vital step in the advanced analysis of GIS ${ }^{[18]}$ whose core is both analysis and measurement of spatial correlation. From the global and local dimensions, we employ Global Moran's I and Getis-Ord $G^{*}$ to explore patterns of Chinese fishery geographic agglomeration, and as follows:

$$
\begin{aligned}
& \text { 1) Global Moran's I } \\
& \qquad I=\frac{\sum_{i=1}^{n} \sum_{j=1}^{n}\left(X_{i}-\bar{X}\right)\left(Y_{j}-\bar{Y}\right)}{S^{2} \sum_{i=1}^{n} W_{i j}}
\end{aligned}
$$

Where $\mathrm{n}$ is equal to 30 which corresponds to the total number of basic spatial units; $X_{i}, Y_{j}$ represent fishery product yields of region $\mathrm{i}$ and $\mathrm{j}$ respectively, and $\bar{X}$ denotes the average fishery product yields; $S^{2}=\sum_{i=1}^{n}\left(X_{i}-\bar{X}\right)^{2} / n$; Simultaneously, at a given significant level, if the value of $I$ is positive, then it indicates that the similar observed values tend to gather in space; If negative, those tend to disperse in space; and When the value of $I$ is close to that of $E$ (I), which demonstrates that the observed values are independent with each other, in other words, fishery production shows a random distribution independently.

2) Getis-OrdG $_{\mathrm{i}}^{*}(\mathrm{~d})$

$$
G_{i}^{*}(d)=\frac{\sum_{j=1}^{n} W_{i j}(d) X_{j}}{\sum_{j=1}^{n} X_{j}}
$$

To facilitate the interpretation and comparison, we will standardize $\mathrm{Gi}^{*}(\mathrm{~d})$ : 


$$
\mathrm{Z}\left(G_{i}^{*}\right)=\frac{G_{i}^{*}-E\left(G_{i}^{*}\right)}{\sqrt{\operatorname{Var}\left(G_{i}^{*}\right)}}
$$

Where $X_{j}$ is the fishery product yields of region $\mathrm{j}$; $\mathrm{d}$ and $\mathrm{W}_{\mathrm{ij}}(\mathrm{d})$ represent the distance scale and weight respectively; $\mathrm{E}\left(\mathrm{G}_{\mathrm{i}}^{*}\right)$ and $\operatorname{Var}\left(\mathrm{G}_{\mathrm{i}}^{*}\right)$ denote the mathematical expectation and variance coefficient of $\mathrm{Z}\left(\mathrm{G}_{\mathrm{i}}^{*}\right)$ respectively; At a given significance level, if the value of $\mathrm{Z}\left(\mathrm{G}_{\mathrm{i}}^{*}\right)$ is positive, then it indicates that the observed value of neighboring areas around region I is relatively high (above average value), and those areas are considered to be hot spots; But if negative, those are just relatively low (below average value), and those ones are considered to be cold spots.

\section{THE TIME-SERIES CHANGES AND BARYCENTRIC SHIFT OF FISHERY GEOGRAPHIC AGGLOMERATION IN CHINA}

\section{A. The time-series changes of fishery geographic agglomeration degree}

Fig.1 shows the changes of the Gini coefficient and moran'I of Chinese fishery in the period from 1988 to 2013. It is noticeable that the value of Gini coefficient is always above 0.68 and its average value is also close to 0.7 , and clearly, as you can see that the overall trend of the line of Gini coefficient has showed a slow decline in the study periods. Additionally, we also can find that the value of moran'I is always positive, that is to say, the phenomenon of fishery geographic agglomeration exists in China. According to the line of moran'I in Fig.1, it is founded that the early stage of agglomeration is not stable, but it is strengthening. Taken together,

Chinese fishery production tends to cluster at provincial level and has an uneven distribution obviously. The degree of uneven distribution of fishery production tends to narrow in the national perspective; nevertheless, that is the opposite in the local perspective. Obviously, the complex situation above is considerable relevance to industrial characteristics and development stages of Chinese fishery.

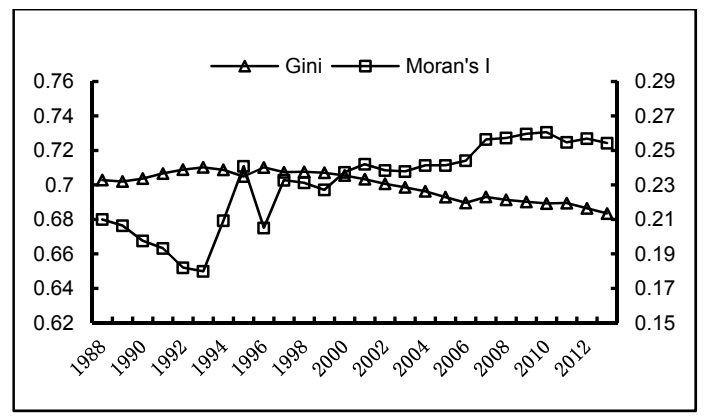

Fig. 1. Gini coefficient and Moran'I changes of fishery in China during 1988 $-2013$

\section{B. The barycentric shift of fishery}

Fig.2 shows the barycentric shift of Chinese fishery in the period from 1988 to 2013. In Fig.2, the map shows that the whole fishery barycenter are in the city of the lower reaches of Yangtze River, namely, Anqing city of Anhui province. Overall, Comparing with the geometry center of China $\left(103^{\circ} 50^{\prime} \mathrm{E}, 36^{\circ} \mathrm{N}\right)$, the fishery barycenter is always located at the southeast in the 26 years. Meanwhile, in the view of evolution of both direction and path, we also can find that the longitude of fishery barycenter decreased from $116^{\circ} 42^{\prime}$ to $115^{\circ} 54^{\prime}$ and the latitude of fishery barycenter decreased from $30^{\circ} 54$ to $30^{\circ} 30^{\prime}$ in study periods. And the changes of fishery barycenter may be a little narrow and slightly rotated, but the evolution of fishery barycenter tended to the southwest, particularly at the early 21 st century, showing a clearer trend toward the west. Beyond that, its tracks are similar to the flow of the Yangtze River.

The change trend of fishery barycenter which is from the coast to the inland is closely associated with both the development of freshwater culture and the improvement of the whole management system of marine fishery resources in China in recent years.

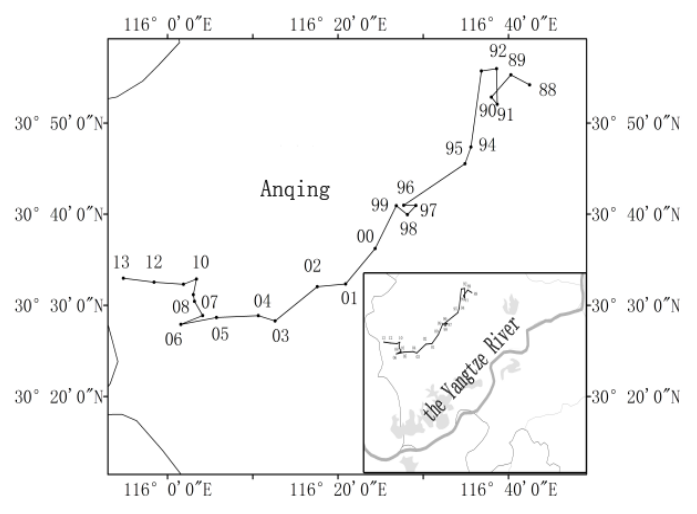

Fig. 2. The change track of fishery barycenter in China during 1988-2013

\section{THE PATTERN EVOLUTION OF CHINESE FISHERY GEOGRAPHIC AGGLOMERATION}

Using ArcGis10.1, we obtained maps of the pattern evolution of Chinese fishery geographic agglomeration on the basis of the output data fishery products in 1988, 1999 and 2013 as Fig.3.

In Fig.3, applying equation (5) and the Jenks method, the whole research region was divided into 4 types of areas, namely, hot spots, sub hot spots, sub cold spots and cold spots. Results of Chinese fishery geographic agglomeration are summarized from the national, regional and provincial scales as follows:

\section{A. National scale}

On the whole, Chinese fishery geographic agglomeration always exhibits the spatial patterns of hot spots in coastal regions and cold spots in inland regions in1988, 1999 and 2013. This is line with realistic development of Chinese fishery.

\section{B. Regional scale}

(1) The number of hot and sub hot spots has decreased by nearly half for 26years and had only 7 in 2013. Conversely, that of cold and sub cold spots has increased to 23 from 18 in the corresponding times.

(2) There are 19 type areas which accounted for $63.3 \%$ of the whole research units and have not changed for 26 years. 


\section{$\triangle$ ATLANTIS PRESS}

That implied that the fishery geographic agglomeration is relatively stable, and its stability was determined by immovable natural resources, for example, fishing resources.

(3)There are 11 type areas which have changed for 26 years. And they mainly showed the gradually weakened evolution characteristics.

(4) The initially clear contiguous distribution and apparently gradient lapse from northwest to southeast of various type areas became less obvious or more complicated.

\section{Provincial scale}

(1) As developed provinces of fishery in coastal regions of China, the yields of fishery products of Shandong, Guangdong, Fujian, Zhejiang, Jiangsu and Liaoning provinces are still ranked 1-6 respectively in 2013. But in terms of the change of patterns, these provinces have differentiated into two categories: the former three provinces were still hot spots; and the next was back to sub hot spots owing to different causes.
(2) As developed provinces whose output of fishery production exceeded 2 million tons, Hubei, Guangxi, Jiangxi, Hunan, Anhui were ranked 7 th to 11 th throughout the country in 2013. In terms of the change of patterns, Hubei province was still sub hot spots, but the others have retreated to cold spots.

(3) Hainan, Sichuan and Hebei provinces along the coast or river were superior in resources, but they were still sub cold spots because of various reasons.

(4) 12 other provinces were always cold spots due to different reasons. The reasons for Jilin, Beijing, Inner Mongolia, Shanxi, Yunnan, Guizhou provinces were the unreasonable layout of freshwater culture and poor yields per unit. And the lack of water areas and precipitation led to the results for Xinjiang, Gansu, Shaanxi, Ningxia provinces. Yet, the harsh climate and fragile ecological environment were the main cause for Tibet and Qinghai provinces.
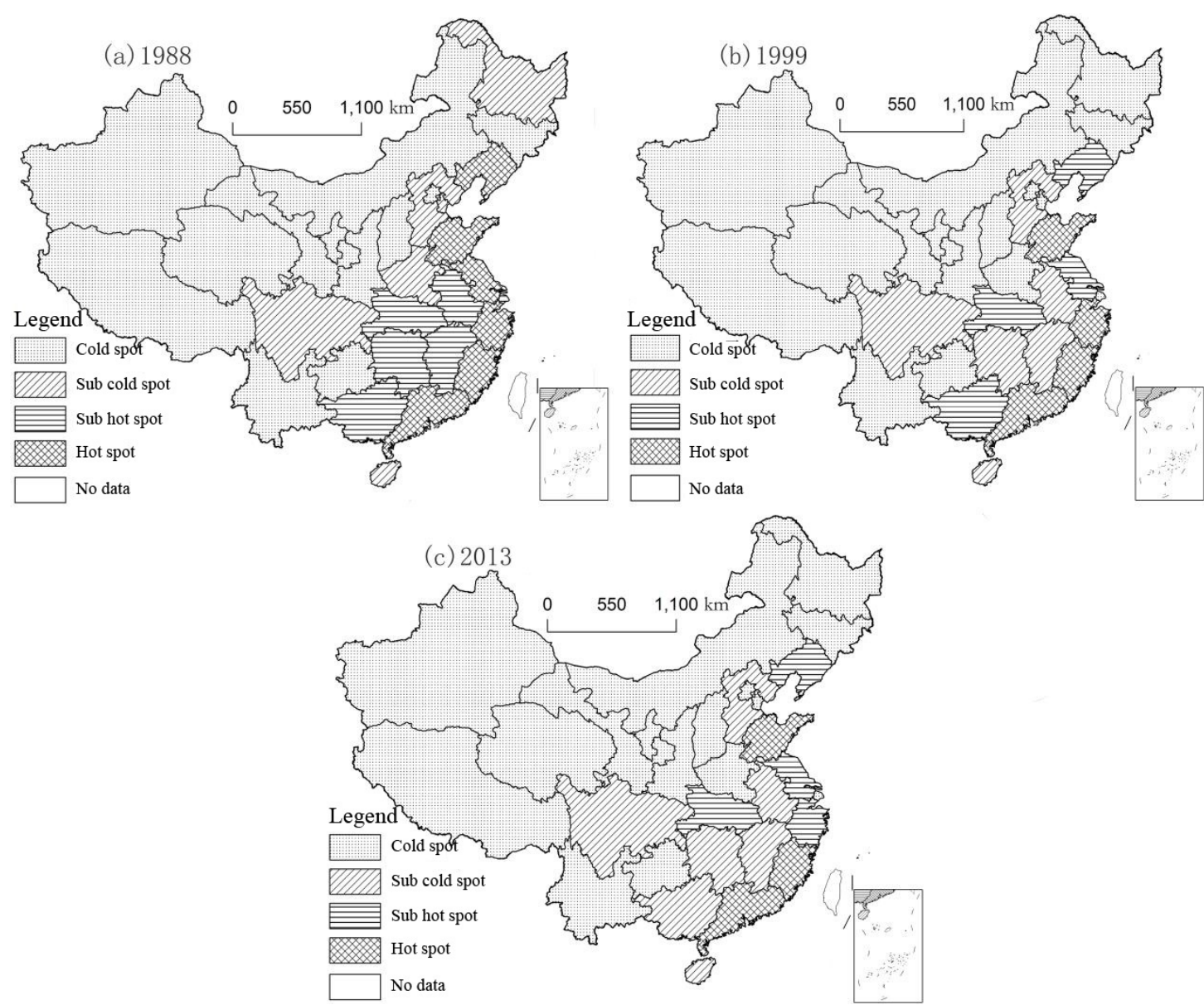

Fig. 3. The pattern Evolution of geographical agglomeration of Chinese fishery

\section{CONClusion}

Through the analysis of the spatial-temporal characteristics and pattern evolution of Chinese fishery geographic agglomeration for the period from 1988 to 2013, the conclusions are drawn as follows:
(1) Chinese fishery production tends to cluster at provincial level and has an uneven distribution obviously in the study periods, and the degree of unbalanced distribution tends to narrow in the national perspective, but that is the opposite in the local perspective. 
(2) The fishery barycenter is always located at the southeast in the 26 years. And its tracks are similar to the flow of the Yangtze River.

(3) Chinese fishery geographic agglomeration always exhibits the spatial patterns of hot spots in coastal regions and cold spots in inland regions. And the number of hot and sub hot spots has decreased by nearly half, Conversely, that of cold and sub cold spots has relatively increased for 26years. But most of type areas haven't changed, and the changed areas, mainly showed the gradually weakened evolution characteristics. Meanwhile, the initially clear contiguous distribution and apparently gradient lapse from northwest to southeast of various type areas became less obvious or more complicated. Generally speaking, natural factors and regional differences which include location, resources, hydrology, geomorphology, climate, industrial structure and layout, technical level will influence the pattern evolution.

\section{REFERENCES}

[1] Krugman P. Geography and Trade. Cambridge, MA: MIT Press, 1991.

[2] ZHANG H, LIANG J S. Progress in industrial agglomeration research. Progress in Geography, 2007, 02: 14-24. (In Chinese)

[3] HE C F, PAN F H, SUN L. Geographical concentration of manufacturing industries in China. Acta Geographica Sinica, 2007, 62(12): 1253-1264. (In Chinese)

[4] LI J M, SUN T S, ZHANG W Z. Spatial cluster characteristics and modes of producer services in China. Scientia Geographica Sinica, 2014, 34(4): 385-393. (In Chinese)

[5] DENG J Q. World agricultural concentration: situation, motivation and mechanism. Issues In Agricultural Economy, 2010, (9): 17-25. (In Chinese)
[6] Porter M E. Location, competition, and economic development: local clusters in a global economy [J]. Economic Development Quarterly, 2013, 14(1): 15-34.

[7] XIAO W D. Analysis on the spatial-temporal features and developing trend and effects of agricultural geographic agglomeration in China. Chinese Rural Economy, 2012,05: 19-31. (In Chinese)

[8] WANG G G, WANG M L, YANG C. Characteristics and Mechanism of Animal Husbandry's Geographical Agglomeration in China. Journal of Natural Resources, 2014,12: 2137-2146. (In Chinese)

[9] DENG Z B, FENG Y G, ZHANG J L, et al. Empirical studies on the regional pattern changes of grain production and its main contributing factors in China. Macroeconomics, 2014(3): 94-113. (In Chinese)

[10] JIE M S, XUE Y, XUE L. Study on cotton production's spatial distribution, changes and influencing factors in China. Research of Agricultural Modernization, 2015,(3):387-393. (In Chinese)

[11] WU J Z, SHEN C, WANG S W, et al. Spatial evolution, mechanism, effect and policies of vegetable production agglomeration in China. Scientia Agricultura Sinica,2015, 48(8): 1641-1649. (In Chinese)

[12] WANG W X, XIANG Y, QI C J. Study on geographic agglomeration of fruit industry in China: spatial-temporal characteristics and affecting factors. Economic Geography, 2013, 08: 97-103. (In Chinese)

[13] WANG G G, WANG M L, WANG J, et al. Spatial-temporal dynamics and its influencing factors of herbivorous livestock breeding in China. Acta Geographica Sinica, 2015,70(7):1091-1100. (In Chinese)

[14] LIU T J, FAN Y. Analysis of the influencing factor and layout of major apple production in China. Issues in Agricultural Economy, 2012, (10): 36-42. (In Chinese)

[15] XU H Y, ZHU H Y. Spatial change of China's grain production based on geographical division of natural factors during 1990-2010. Acta Geographica Sinica, 2015, 70(4): 582-590. (In Chinese)

[16] LOU D, GU S Z. Fishery resources spatial distribution of fishery and its evolution in China.Chinese Journal of Agricultural Resources and Regional Planning, 2005,26(1): 27-31. (In Chinese)

[17] LI E L, PANG A C, ZHU J G. Analysis of the evolution path and mechanism of china's agriculture agglometration and geographic pattern.Geographic Research, 2012,05: 885-898. (In Chinese)

[18] Bao Y C, Li X. Spatial data analysis and spatial models [J].Geographical Research, 1999, 18(2): 185-190. (In Chinese) 